Research Article

\title{
SLAM/SAP Decreased Follicular Regulatory T Cells in Patients with Graves' Disease
}

\author{
Lina Geng, ${ }^{1}$ Jun Yang, ${ }^{1}$ Xinyi Tang, ${ }^{1}$ Huiyong Peng, ${ }^{1}$ Jie Tian, ${ }^{2}$ Zhigang Hu $\left(D,{ }^{3}\right.$ \\ Yingzhao Liu $\left(\mathbb{0},{ }^{4}\right.$ Huaxi $\mathrm{Xu}^{2}{ }^{2}$ and Shengjun Wang $\mathbb{D}^{1,2}$ \\ ${ }^{1}$ Department of Laboratory Medicine, Affiliated People's Hospital, Jiangsu University, Zhenjiang, China \\ ${ }^{2}$ Institute of Laboratory Medicine, Jiangsu Key Laboratory for Laboratory Medicine, Jiangsu University School of Medicine, \\ Zhenjiang, China \\ ${ }^{3}$ Department of Laboratory Medicine, Wuxi Children's Hospital, Wuxi People's Hospital Affiliated to Nanjing Medical University, \\ Wuxi 214023, China \\ ${ }^{4}$ Department of Endocrinology, Affiliated People's Hospital, Jiangsu University, Zhenjiang, China
}

\begin{abstract}
Correspondence should be addressed to Zhigang Hu; jswxhzg@163.com, Yingzhao Liu; zjliuyingzhao@126.com,
\end{abstract} and Shengjun Wang; sjwjs@ujs.edu.cn

Received 18 January 2021; Revised 9 March 2021; Accepted 30 March 2021; Published 20 April 2021

Academic Editor: Lihua Duan

Copyright (C) 2021 Lina Geng et al. This is an open access article distributed under the Creative Commons Attribution License, which permits unrestricted use, distribution, and reproduction in any medium, provided the original work is properly cited.

\begin{abstract}
Signaling lymphocytic activation molecule (SLAM) and SLAM-associated protein (SAP) play important role in inflammatory and autoimmune diseases. Our study is aimed at detecting the expression of SLAM and SAP in patients with Graves' disease (GD) and analyzing the effect of SLAM/SAP on circulating blood CD $4^{+}$CXCR $5^{+}$Foxp $3^{+}$follicular regulatory $\mathrm{T}$ (Tfr) cells. The level of SAP in $\mathrm{CD}^{+} \mathrm{CXCR}^{+} \mathrm{T}$ cells and the level of SLAM on $\mathrm{CD} 19^{+} \mathrm{B}$ cells were significantly increased in the patients with GD, but no significant difference in the level of SLAM on $\mathrm{CD}^{+}{ }^{+} \mathrm{CXCR} 5^{+} \mathrm{T}$ cells was observed between the patients with GD and the healthy controls. A decrease in the percentage of Foxp $3^{+}$cells in $\mathrm{CD}^{+}{ }^{+} \mathrm{CXCR} 5^{+} \mathrm{T}$ cells was observed following anti-SLAM treatment, but the percentages of IFN- $\gamma^{+}$cells, IL- $4^{+}$cells, and IL- $17^{+}$cells showed no obvious differences. The proportion of circulating Tfr cells was decreased in the patients with GD, and the proportion of circulating Tfr cells had a negative correlation with the level of SAP in $\mathrm{CD}^{+} \mathrm{CXCR}^{+} \mathrm{T}$ cells and the levels of autoantibodies in the serum of the patients with GD. Our results suggested that the SLAM/SAP signaling pathway is involved in the decrease of circulating Tfr cells in Graves' disease.
\end{abstract}

\section{Introduction}

Graves' disease (GD) is an organ-specific autoimmune disease with a complex pathogenesis that involves aberrant $\mathrm{B}$ and $\mathrm{T}$ lymphocyte responses. Patients with GD produce excess autoantibodies, such as anti-thyroid-stimulating hormone (TSH) receptor antibody (TR-Ab), anti-thyroperoxidase antibody (TPO-Ab), and anti-thyroglobulin antibody (TG-Ab) [1]. TR-Ab, whose positive rate in patients with untreated GD is as high as $85-100 \%$, interacts with the TSH receptor to stimulate thyroid follicular cell hyperplasia and promote thyroid hormone synthesis and secretion [1].

The $\mathrm{CD}^{+} \mathrm{T}$ cell-mediated immune response has long been regarded as an important aspect of the pathogenesis of
Graves' disease. Many studies have shown that Th1, Th2, and Th17 cells, which are subtypes of $\mathrm{CD} 4^{+} \mathrm{T}$ cells, are effector helper $\mathrm{T}$ cells that participate in the pathogenesis of Graves' disease [2-4]. However, we recently found that follicular helper $\mathrm{T}(\mathrm{Tfh})$ cells are involved in the pathogenesis of this disease $[5,6]$. Tfh cells are a new subset of $\mathrm{CD}^{+} \mathrm{T}$ cells characterized by the transcription factor Bcl-6 (B cell lymphoma 6) as well as the expression of $\mathrm{C}-\mathrm{X}-\mathrm{C}$ chemokine receptor type 5 (CXCR5), inducible costimulatory molecule (ICOS), programmed cell death protein 1 (PD-1), and interleukin-21 (IL-21). In addition to generating memory B cells and plasma cells, Tfh cells are required for the formation and maintenance of the germinal center (GC). Tfh cells provide survival signals to GC B cells via multiple pathways, 
including CD40L, IL-4, IL-21, PD-1, signaling lymphocytic activation molecule (SLAM), and SLAM-associated protein (SAP) [7]. Our previous studies showed that the percentage of circulating Tfh cells in patients with GD was increased, which is related to the disease process [5], but the molecules and mechanisms involved in this process are unclear.

In recent years, researchers have found that peripheral blood $\mathrm{CD} 4^{+} \mathrm{CXCR}^{+} \mathrm{T}$ cells can be divided into several different subgroups: Tfh 1 cells mainly secrete interferon- $\gamma$ (IFN- $\gamma$ ), Tfh 2 cells mainly secrete IL-4, and Tfh 17 cells mainly secrete IL-17 and IL-22 [8]. In addition, Lim and colleagues have found follicular regulatory $\mathrm{T}$ ( $\mathrm{Tfr}$ ) cells in the germinal center of the human tonsil, and these cells had immunosuppressive functions [9]. Although Tfr cells express some of the same markers as Tfh cells, such as Bcl-6, CXCR5, PD-1, ICOS, and SAP, Tfr cells usually develop from Treg cells but not Tfh cells [10-12]. Tfr cells can inhibit Tfh cells or induce B cell death to regulate the GC reaction $[13,14]$. In contrast, Tfh cells can limit the proliferation of Tfr cells by secreting IL-21 $[15,16]$. In recent years, a number of studies have reported on the immune disorders of Tfr/Tfh cells in the peripheral blood of patients with autoimmune diseases such as rheumatoid arthritis (RA), multiple sclerosis (MS), myasthenia gravis, and systemic lupus erythematosus (SLE) $[17,18]$.

SLAM is a type I transmembrane glycoprotein; it forms homophilic interactions and acts as a self-ligand [19-22]. SLAM is mainly expressed in thymus cells, B cells, activated T cells, dendritic cells, macrophages, and activated mononuclear cells [23-25]. Stimulating TCR activation can induce the expression of SLAM in immune cells; then, SLAM amplifies TCR signaling [26, 27]. After tyrosine phosphorylation of the immunoreceptor tyrosine-based switch motif (ITSM) in the intracellular domain of SLAM, the SLAMSAP-Fyn compound is formed and then initiates intracellular signal transduction [28, 29]. The SLAM-SAP signaling pathway has been reported to induce the synthesis of Th2 cytokines and decrease the Th1 immune response [27]. Moreover, SAP deficiency damages the germinal center and reduces the number of antigen-specific memory $B$ cells and plasma cells [30, 31]. An increase in the expression of SLAM or SAP has been observed in autoimmune diseases and allergic disease [32-35]. In addition, SLAM is a potential target for inflammatory and autoimmune diseases [36].

Because SLAM and SAP have been shown to be important in Tfh-B cell interactions, we asked whether these two molecules play a role in the pathogenesis of GD. We found that in patients with GD, the expression of SLAM on $\mathrm{CD}_{19}{ }^{+} \mathrm{B}$ cells and SAP in $\mathrm{CD}^{+} \mathrm{CXCR}^{+} \mathrm{T}$ cells was increased, the proportion of peripheral blood $\mathrm{CD} 4^{+} \mathrm{CXCR} 5^{+-}$ Foxp $3^{+}$Tfr cells was decreased, and costimulation of SLAM along with CD3/TCR stimulation potently decreased the proportion of Tfr cells in vitro. Collectively, our results indicate that the SLAM/SAP signaling pathway may be involved in the pathogenesis of Graves' disease.

\section{Materials and Methods}

2.1. Individuals and Samples. All GD patients included in our studies were recruited from the Affiliated People's Hospital of
Jiangsu University and newly diagnosed according to clinically and biochemically verified hyperthyroidism. Thirtyfive age- and sex-matched healthy individuals were included as controls, including 27 females and 8 males, ranging from 28 to 50 years old. They had no history of GD or any other related diseases. The main clinical data and laboratory test indicators of the patients are shown in Table 1. All indicators were measured by chemiluminescent immunoassays according to the manufacturer's protocol. All blood samples were obtained in accordance with the regulations and approval of the Affiliated People's Hospital of Jiangsu University.

2.2. Cell Isolation and Purification. Peripheral blood mononuclear cells (PBMCs) were isolated by density gradient centrifugation over Ficoll-Hypaque solution. Untouched $\mathrm{CD}^{+} \mathrm{T}$ cells were purified from PBMCs using a CD4 ${ }^{+} \mathrm{T}$ Cell Isolation Kit (Miltenyi Biotec $\mathrm{GmbH}$, Bergisch Gladbach, Germany). $\mathrm{CD}^{+} \mathrm{CXCR}^{+} \mathrm{T}$ cells were purified from $\mathrm{CD} 4^{+}$ $\mathrm{T}$ cells by FITC-conjugated anti-human CXCR5 mAb and anti-FITC MicroBeads (Miltenyi Biotec $\mathrm{GmbH}$, Bergisch Gladbach, Germany). All operations are based on the manufacturer's instructions.

2.3. Cell Culture and Stimulation. Ninety-six-well cell culture plates were precoated with $0.5 \mathrm{mg} / \mathrm{ml}$ anti-CD3 $\mathrm{mAb}$ (clone OKT3; eBioscience, San Diego, CA) for $2 \mathrm{~h}$, and then, purified $\mathrm{CD} 4^{+} \mathrm{CXCR} 5^{+} \mathrm{T}$ cells from healthy control subjects were cultured for $48 \mathrm{~h}$ in the plates $\left(1 \times 10^{5}\right.$ cells/well $)$ with $100 \mu \mathrm{l}$ of culture medium (Miltenyi Biotec) in the presence of antiSLAM mAb (clone A12 (7D4); BioLegend, San Diego, CA).

2.4. RNA Isolation and Real-Time PCR. TRIzol reagent (Invitrogen, Carlsbad, CA) was added to the purified CD $4^{+} \mathrm{T}$ cells following the manufacturer's instructions to extract RNA. Then, reverse transcription was performed according to the manufacturer's instructions (Toyobo, Osaka, Japan). Next, real-time PCR was performed in duplicate with Bio-Rad SYBR Green Supermix (Bio-Rad, Hercules, CA). Primer sequences were as follows: SLAM: forward $5^{\prime}$-ACCGTG AGCAACCCTATCAG-3', reverse $5^{\prime}$-CCCTAACAGCC CAGCATACA-3'; SAP: forward $5^{\prime}$-GGACGCAGTGG CTGTGTAT-3', reverse $5^{\prime}$-TGGCACGCTCTCGCTGT-3'. Each gene was normalized to $\beta$-actin with the following primers: forward $5^{\prime}$-CACGAAACTACCTTCAACTCC- $3^{\prime}$, reverse $5^{\prime}$-CATACTCCTGCTTGCTGATC-3'. Data were analyzed by Bio-Rad CFX Manager software.

2.5. Flow Cytometry Analysis. Anticoagulant blood was stained with FITC-conjugated anti-CD19 (clone HIB19; BioLegend) and phycoerythrin- (PE-) conjugated anti-SLAM (clone A12 (7D4); eBioscience) mAb after lysing red blood cells (BD Pharmingen) to detect the expression of SLAM on $\mathrm{CD} 19^{+} \mathrm{B}$ cells in peripheral blood.

PBMCs were washed and stained with phycoerythrincy5-conjugated anti-CD3 (clone OKT3; eBioscience), APCconjugated anti-CD4 (clone A161A1; BioLegend), and Alexa Fluor 488-conjugated anti-CXCR5 (clone RF8B2; BD Pharmingen) $\mathrm{mAb}$. Half of the cells were stained with PEconjugated anti-SLAM, and the other half of the cells were 
TABLE 1: Clinical features of the patients with GD and healthy controls included in this study.

\begin{tabular}{lccc}
\hline & Patients with GD & $\begin{array}{c}\text { Healthy } \\
\text { controls }\end{array}$ & Range \\
\hline Gender (M/F) & $5 / 32$ & $8 / 27$ & \\
Age (year) & $40.81 \pm 13.13$ & $37.13 \pm 11.89$ & \\
FT3 (pmol/l) & $11.22 \pm 9.00$ & $4.15 \pm 1.23$ & $3.10-6.00$ \\
FT4 (pmol/l) & $25.13 \pm 13.19$ & $12.78 \pm 4.11$ & $7.86-17.41$ \\
TSH (uIU/ml) & $0.03 \pm 0.02$ & $3.34 \pm 1.18$ & $0.34-5.60$ \\
TR-Ab (U/l) & $75.39 \pm 115.04$ & $13.58 \pm 11.70$ & $0-30$ \\
TPO-Ab (IU/ml) & $917.91 \pm 1099.29$ & $3.70 \pm 3.19$ & $0-9$ \\
TG-Ab (IU/ml) & $329.83 \pm 718.06$ & $2.39 \pm 1.34$ & $0-4$ \\
\hline
\end{tabular}

Data correspond to the arithmetic mean \pm SD. M: male; F: female.

stained with PE-conjugated anti-SAP (clone XLP-1D12; eBioscience) after permeabilization (Invitrogen). Other PBMCs were stained with APC-conjugated anti-CD4, Alexa Fluor 488-conjugated anti-CXCR5, and PE-conjugated antiFoxp3 (clone REA1253; Miltenyi Biotec) mAb to detect the proportion of Tfr cells in peripheral blood.

Cultured $\mathrm{CD}^{+} \mathrm{CXCR}^{+} \mathrm{T}$ cells in some of the wells were collected and stained with PE-conjugated anti-Foxp3 $\mathrm{mAb}$ to detect the proportion of Tfr cells. For detection of cytokines [37], PMA (50 ng/ml) and ionomycin $(1 \mu \mathrm{g} / \mathrm{ml})$ were added to the CD $4^{+} \mathrm{CXCR}^{+} \mathrm{T}$ cells and cultured for $1 \mathrm{~h}$, and then, BFA $(1 \mu \mathrm{g} / \mathrm{ml}$, for detecting IFN- $\gamma$ and IL- 4$)$ and monensin $(2 \mu \mathrm{g} / \mathrm{ml}$, for detecting IL-17) were added and cultured for $5 \mathrm{~h}$. Then, the cells were collected and added with $1 \mathrm{ml} \mathrm{IC}$ Fixation Buffer (Invitrogen). After mixing, they were treated at $4^{\circ} \mathrm{C}$ for $10 \mathrm{~min}$ and washed twice with $1 \mathrm{ml} 1 \mathrm{x}$ Permeabilization (Invitrogen) and then centrifuged at $4^{\circ} \mathrm{C}$ and $500 \mathrm{~g}$ for $5 \mathrm{~min}$ each time. The supernatant was discarded and $40 \mu \mathrm{l} 1 \mathrm{x}$ Permeabilization was applied to the resuspended cells. Then, the cells were stained with PE-conjugated antiIFN- $\gamma$ (clone REA600, Miltenyi Biotec), PE-conjugated antiIL-4 (clone REA895, Miltenyi Biotec), or PE-conjugated anti-IL-17 mAb (clone N49-653, Miltenyi Biotec).

All staining was performed according to the manufacturers' protocol. Isotype-matched $\mathrm{mAb}$ controls were used in all procedures. Cells were analyzed with a FACSCalibur flow cytometer (Becton Dickinson, Sparks, MD) and BD Biosciences Accuri C6, and the results were analyzed with WinMDI 2.9 software or Accuri C6.

2.6. Statistical Analysis. Two-tailed Student's $t$-test was applied for statistical comparison of two groups. Correlations between variables were determined by Spearman rank test. Data are expressed as the mean \pm SD. A $P$ value of 0.05 or less was considered significant. Data were analyzed with GraphPad Prism 6 software.

\section{Results}

3.1. The Expression of SLAM and SAP in the Peripheral Blood of Patients with GD. Many studies have reported that SLAM or SAP is elevated in some autoimmune diseases; thus, we investigated whether the expression of these two molecules is changed in patients with GD. We first detected the levels of SAP mRNA and SLAM mRNA in circulating $\mathrm{CD}^{+}{ }^{+} \mathrm{T}$ cells and found that both the SAP mRNA level and the SLAM mRNA level were increased significantly in the patients with GD compared to the healthy controls (Figures 1(a) and 1(b)). Then, we analyzed the mean fluorescence intensity (MFI) of SAP in $\mathrm{CD}^{+}{ }^{+} \mathrm{CD} 4^{+} \mathrm{T}$ cells and $\mathrm{CD} 3^{+} \mathrm{CD} 4^{+} \mathrm{CXCR} 5^{+} \mathrm{T}$ cells from PBMCs and found that the expression of SAP was substantially enhanced in these two subsets of cells from the patients with GD compared with the healthy controls (Figures 1(c) and 1(d)). Subsequently, we compared the MFI of SLAM on the surface of $\mathrm{CD}^{+} \mathrm{CD} 4^{+} \mathrm{T}$ cells and $\mathrm{CD}^{+}{ }^{+} \mathrm{CD} 4^{+} \mathrm{CXCR}^{+} \mathrm{T}$ cells, but there was no significant difference between the patients with GD and the healthy controls (Figures 1(e) and 1(f)).

Studies have shown that the interaction between SLAMSLAM on $\mathrm{T}$ cells and B cells plays an important role in humoral immunity, so we analyzed the MFI of SLAM on circulating CD19 ${ }^{+}$B cells. As shown in Figure 1(g), the level of SLAM on $\mathrm{CD} 19^{+} \mathrm{B}$ cells in the patients with GD was higher than that in the healthy controls.

3.2. The Role of SLAM on Circulating $C D 4^{+} C X C R 5^{+} T$ Cells In Vitro. Because the expression of SLAM on $\mathrm{CD}_{19^{+}} \mathrm{B}$ cells and SAP in $\mathrm{CD} 4^{+} \mathrm{CXCR} 5^{+} \mathrm{T}$ cells was both highly expressed in GD, we wondered whether these increased SLAM molecules on $\mathrm{CD} 19^{+} \mathrm{B}$ cells affect circulating $\mathrm{CD} 4{ }^{+} \mathrm{CXCR} 5^{+} \mathrm{T}$ cells. Therefore, we used anti-SLAM mAb with anti-CD3 $\mathrm{mAb}$ to stimulate $\mathrm{CD} 4^{+} \mathrm{CXCR} 5^{+} \mathrm{T}$ cells in vitro. After stimulation, flow cytometry was used to analyze the proportion of IFN- $\gamma^{+}$cells, IL- $4^{+}$cells, IL- $17^{+}$cells, and Foxp3 $3^{+}$cells in the $\mathrm{CD} 4^{+} \mathrm{CXCR} 5^{+} \mathrm{T}$ cells. The proportion of Foxp ${ }^{+}$cells in $\mathrm{CD} 4^{+} \mathrm{CXCR} 5^{+} \mathrm{T}$ cells declined sharply after stimulation, and this reduction caused by anti-SLAM mAb occurred in a concentration-dependent manner (Figures 2(a) and 2(c)). However, the percentage of Foxp $3^{+}$cells in the $\mathrm{CD} 4^{+} \mathrm{T}$ cells remained unaltered after treatment with anti-SLAM mAb together with anti-CD3 mAb (Figure 2(b)). In addition, the proportion of IFN $-\gamma^{+}$cells, IL- $4^{+}$cells, and IL- $17^{+}$cells showed almost no change after treatment with anti-SLAM $\mathrm{mAb}$ (Figures 2(d)-2(f)).

3.3. The Percentage of Tfr Cells Decreased in the Peripheral Blood from the Patients with GD. As anti-SLAM mAb could reduce the ratio of Tfr cells in vitro, we next analyzed the proportion of Tfr cells in the patients with GD. We gated $\mathrm{CD}^{+} \mathrm{CD}^{+} \mathrm{CXCR}^{+} \mathrm{T}$ cells in PBMCs and then identified Foxp $3^{+} \mathrm{T}$ cells as $\mathrm{Tfr}$ cells (Figure 3(a)). As shown in Figure 3(b), the proportion of Tfr cells decreased in the patients with GD compared with the healthy controls. Further, the proportion of Tfr cells was negatively correlated with SAP expression in the patients with GD (Figure 3(c)).

3.4. The Correlations between Tfr Cells and Autoantibodies. TR-Ab, TG-Ab, and TPO-Ab are critical autoantibodies that provide evidence for diagnosis of GD, so we intended to analyze the relationship between the proportion of Tfr cells in peripheral blood and the levels of autoantibodies. The results 


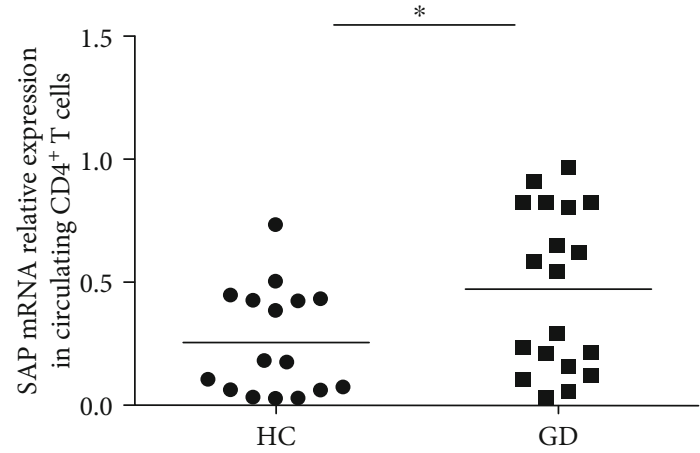

(a)

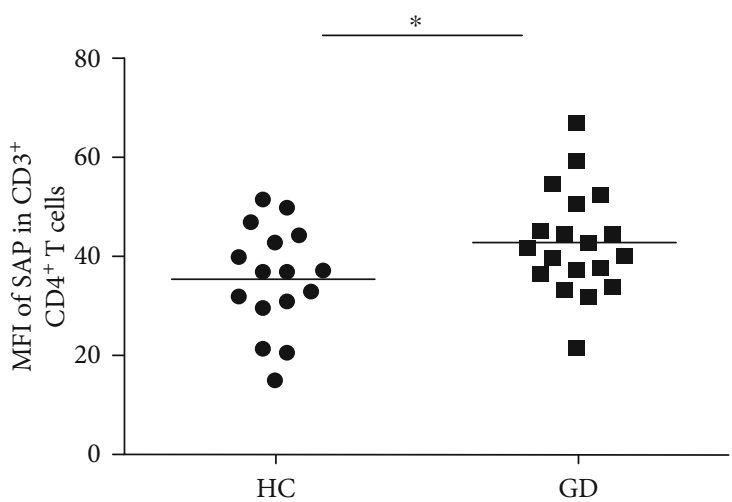

(c)

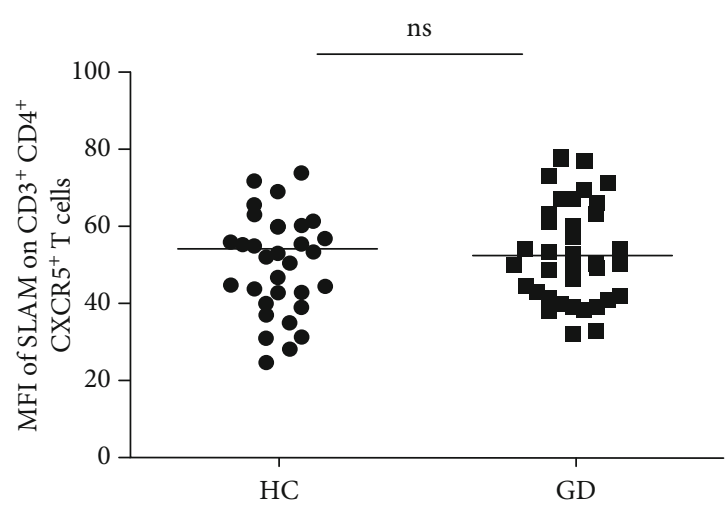

(e)

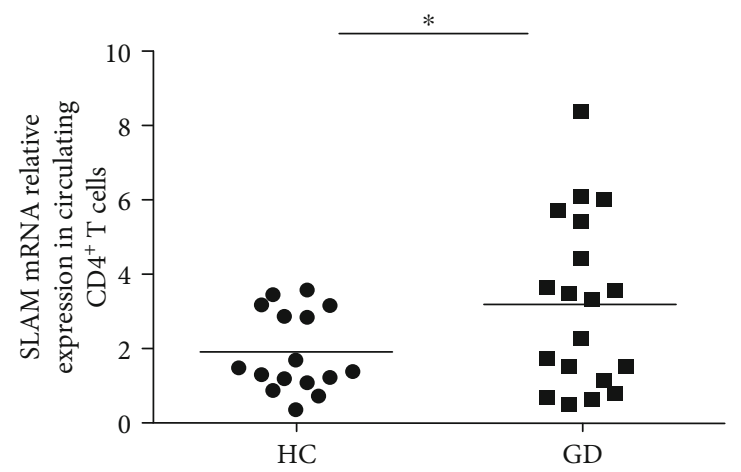

(b)

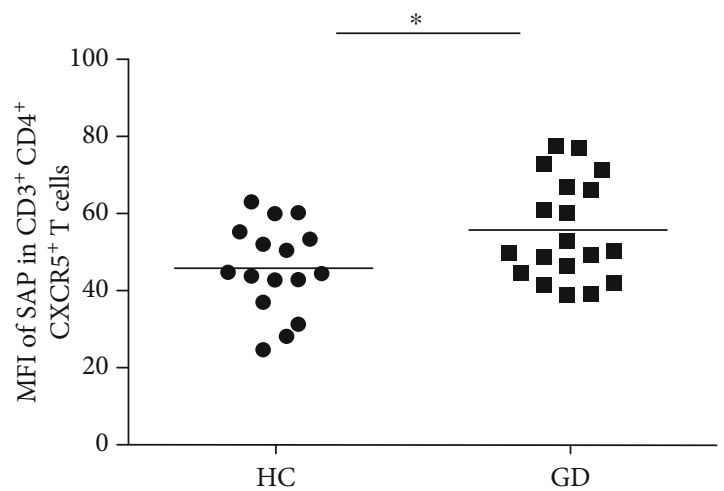

(d)

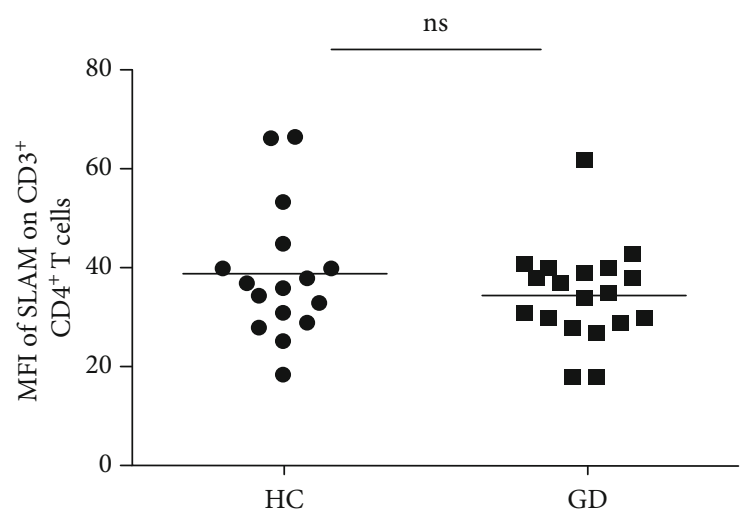

(f)

FIgURe 1: Continued. 


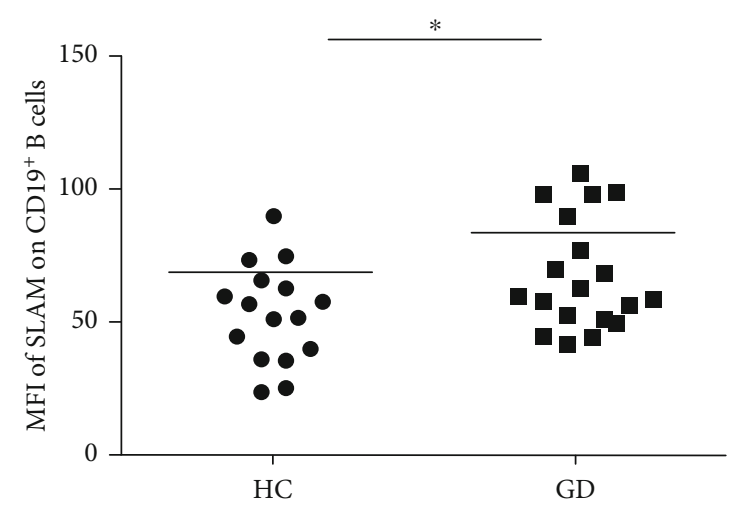

(g)

FIgURE 1: The expression of SLAM and SAP in the peripheral blood of the patients with GD and the healthy controls. The levels of (a) SAP mRNA and (b) SLAM mRNA in circulating $\mathrm{CD}^{+} \mathrm{T}$ cells from the patients with GD and the healthy controls. The mean fluorescence intensity (MFI) of SAP was analyzed by flow cytometry (FCM) in circulating (c) $\mathrm{CD} 4^{+} \mathrm{T}$ cells and (d) CD4 ${ }^{+} \mathrm{CXCR} 5^{+} \mathrm{T}$ cells from the patients with GD and the healthy controls. The MFI of SLAM was analyzed by FCM on circulating (e) CD4 ${ }^{+} \mathrm{T}$ cells and (f) $\mathrm{CD}^{+} \mathrm{CXCR}^{+} \mathrm{T}$ cells from the patients with GD and the healthy controls. (g) The MFI of SLAM was analyzed by FCM on circulating $\mathrm{CD}_{1} 9^{+} \mathrm{B}$ cells from the patients with GD and the healthy controls. Each data point represents an individual subject; horizontal lines show the mean. ${ }^{*} P<0.05, n=19$; ns: no significant differences.

showed that there were negative correlations between the proportion of Tfr cells in PBMCs and the serum concentrations of TR-Ab, TPO-Ab, and TG-Ab in the patients with GD (Figure 4).

\section{Discussion}

Graves' disease is a kind of autoimmune disease in which humoral immunity predominates. Patients produce a variety of autoantibodies to stimulate the proliferation of thyroid follicular cells and then increase the secretion of thyroid hormones, eventually leading to multiple system syndrome. Therefore, autoantibodies in patients with GD are key factors in the pathogenesis of this disease, but the specific pathogenesis has not been fully elucidated. In recent years, researchers have found that the existence of Tfh cells is advantageous to the formation and maintenance of germinal centers and helps B cells differentiate into plasma cells and memory B cells. Tfh-B cell-mediated humoral immunity plays an important role in the pathogenesis of GD. The SLAM-SAP signaling pathway is one of the most important signaling pathways in Tfh cells and plays an important role in Tfh-B cell interactions $[38,39]$. It has been reported that SLAM or SAP is increased in autoimmune diseases [32-34], and thus, we investigated whether SLAM and SAP would be increased in GD. First, we analyzed the expression of SLAM and SAP on $\mathrm{CD}^{+}{ }^{+} \mathrm{T}$ cells and $\mathrm{CD} 4^{+} \mathrm{CXCR} 5^{+} \mathrm{T}$ cells in peripheral blood and found that the level of SAP in the $\mathrm{CD}^{+} \mathrm{T}$ cells and the $\mathrm{CD} 4^{+} \mathrm{CXCR} 5^{+} \mathrm{T}$ cells was increased in the patients with GD. Although the SLAM mRNA level was significantly increased in $\mathrm{CD} 4^{+} \mathrm{T}$ cells from GD patients, but there was no significant difference in SLAM protein on $\mathrm{CD} 4^{+} \mathrm{T}$ cells or $\mathrm{CD}^{+} \mathrm{CXCR}^{+} \mathrm{T}$ cells in peripheral blood between the patients with GD and the healthy controls. Since SLAM on $\mathrm{T}$ cells and B cells acts as a self-ligand, we then detected the level of SLAM on CD19 ${ }^{+}$B cells. Our results showed that the level of SLAM on $\mathrm{CD} 19^{+}$B cells was increased in the patients with GD.

Next, we explored whether the elevated SLAM on CD19 ${ }^{+}$ $\mathrm{B}$ cells had any influence on $\mathrm{CD} 4^{+} \mathrm{CXCR}^{+} \mathrm{T}$ cells, which express high levels of SAP. As early as 1995, researchers used anti-SLAM mAb to stimulate human PBMCs and found that anti-SLAM mAb could activate $\mathrm{T}$ cells and promote $\mathrm{T}$ cell proliferation [40]. Researchers found that mice with SLAMF1/5/6 deficiency showed enhanced humoral immune responses. Although this study suggests that the SLAM molecule may negatively regulate the humoral immune response, there is no specific result showing that a single defect of the SLAMF1 molecule plays a role in the humoral immune response [41]. In addition, we were interested in the studies on SLAMF1 regulating Treg cells, and one of these studies found that the proliferation of Treg cells induced by alloantigen could be inhibited by anti-SLAMF1 mAb [42]. Does this signaling pathway affect Tfr cells? To address this question, we stimulated $\mathrm{CD} 4^{+} \mathrm{CXCR}^{+}{ }^{+}$cells with anti-SLAM mAb in vitro. As expected, the anti-SLAM mAb decreased the proportion of Tfr cells in a concentration-dependent manner, but it did not affect the proportion of Tfh1 cells, Tfh 2 cells, or Tfh 17 cells. Furthermore, although anti-SLAM mAb could decrease the proportion of $\mathrm{CD} 4^{+} \mathrm{CXCR}^{+} \mathrm{Foxp}^{+} \mathrm{Tfr}$ cells, it did not affect the proportion of $\mathrm{CD}^{+}{ }^{+} \mathrm{Foxp}^{+}$Treg cells.

Tfr cells are developed from Treg cells, which are present in the germinal center, and play a role in inhibiting the reaction of the germinal center, limiting the number of Tfh cells and reducing the production of antibodies. Many studies have shown that $\mathrm{Tfh} / \mathrm{Tfr}$ disorders play an important role in the pathogenesis of autoimmune diseases, and the correction of Tfh/Tfr may become a new way to treat autoimmune diseases $[16,43]$. It has been reported that in the BXD2 mouse model of autoimmune disease, IL-21 increased the percentage of Tfh/Tfr cells and the number of Tfh cells to promote the formation of the germinal center; accordingly, 

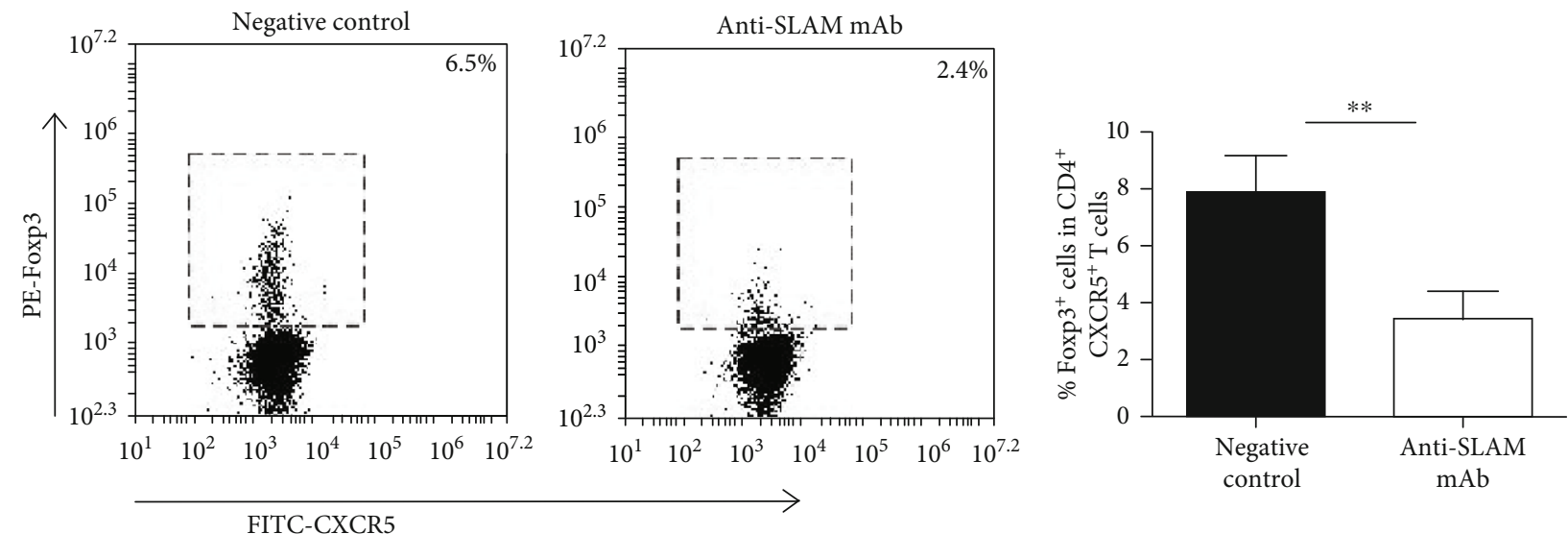

(a)
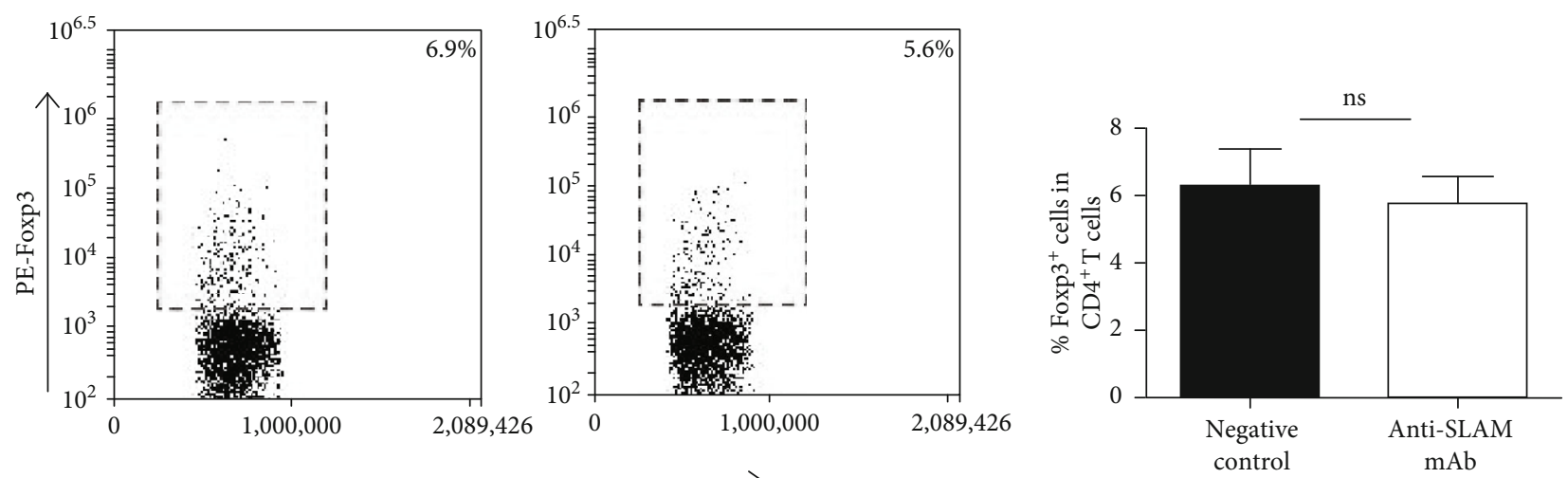

FSC-Height

(b)

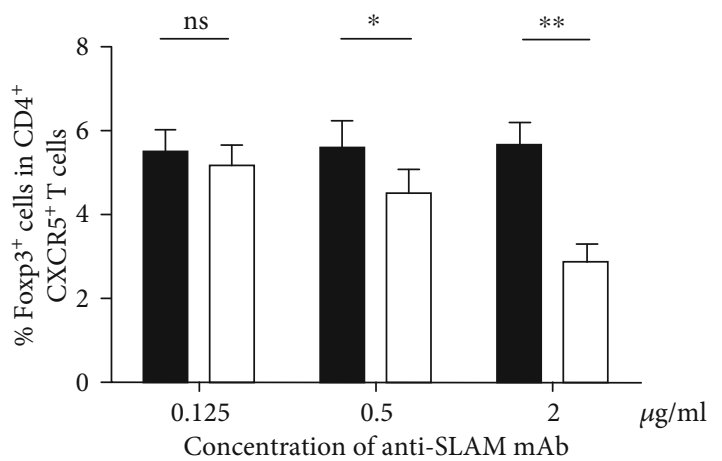

Negative control Anti-SLAM mAb

(c)

Figure 2: Continued. 

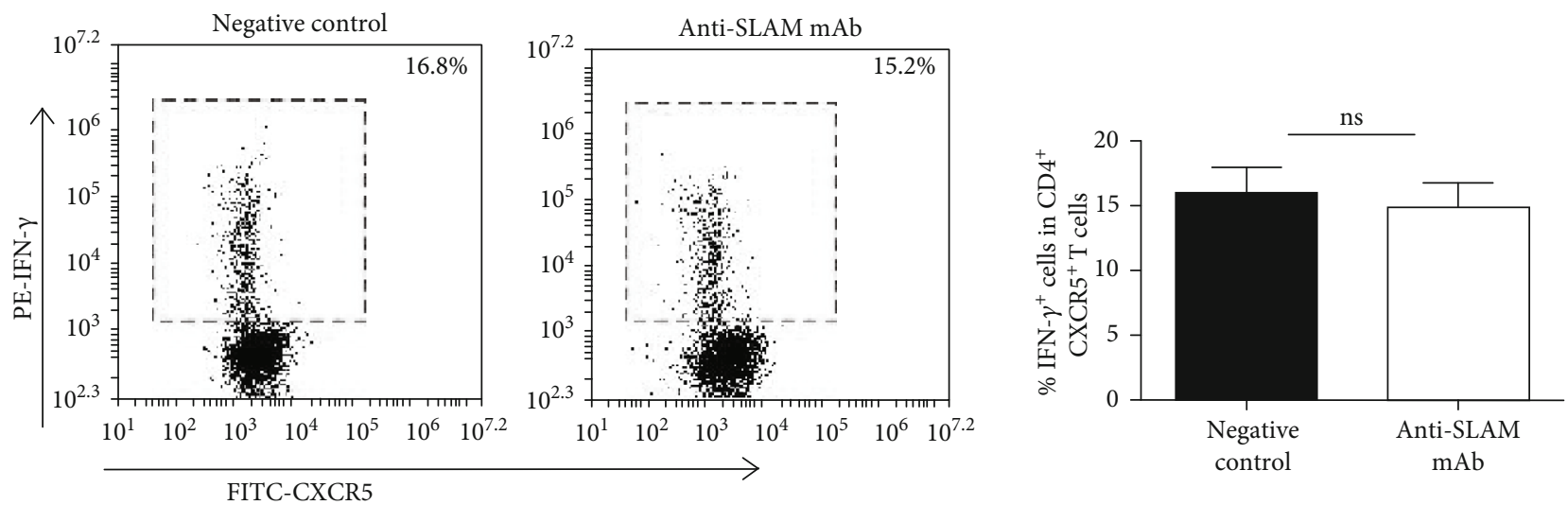

(d)
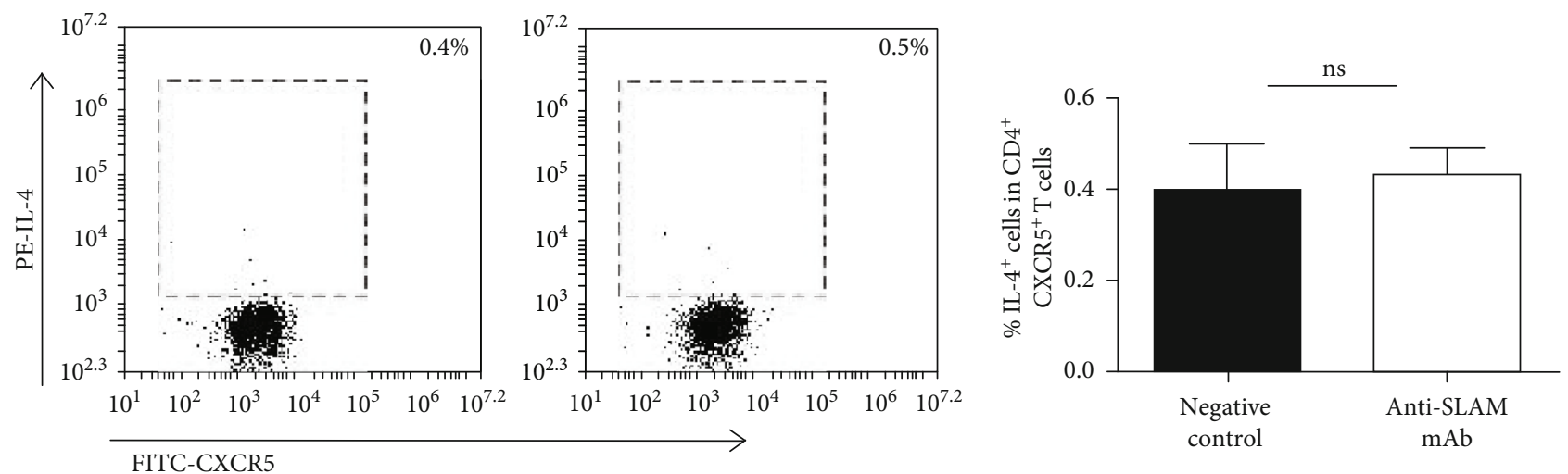

(e)
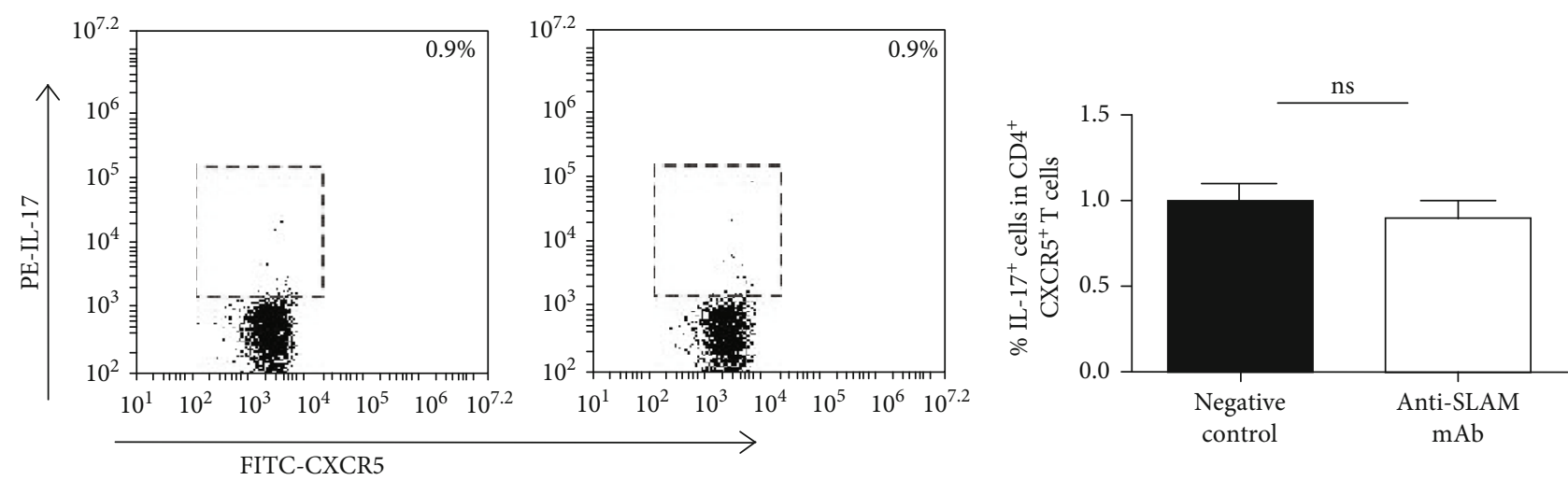

(f)

FIgure 2: The role of SLAM on circulating CD4 ${ }^{+} \mathrm{CXCR}^{+} \mathrm{T}$ cells. Addition of $0.5 \mu \mathrm{g} / \mathrm{ml}$ anti-CD3 mAb and $2 \mu \mathrm{g} / \mathrm{ml}$ anti-SLAM mAb to $\mathrm{CD}^{+} \mathrm{CXCR}^{+} \mathrm{T}$ cells, followed by determination of the percentage of (a) Foxp3 $3^{+}$cells, (d) INF- $\gamma^{+}$cells, (e) IL- $4^{+}$cells, and (f) IL- $17^{+}$ cells. (b) Addition of $0.5 \mu \mathrm{g} / \mathrm{ml}$ anti-CD3 $\mathrm{mAb}$ and $2 \mu \mathrm{g} / \mathrm{ml}$ anti-SLAM $\mathrm{mAb}$ to CD4 ${ }^{+} \mathrm{T}$ cells and detection of the percentage of Foxp3 ${ }^{+}$ cells. (c) Addition of $0.5 \mu \mathrm{g} / \mathrm{ml}$ anti-CD3 $\mathrm{mAb}$ with $0.125 \mu \mathrm{g} / \mathrm{ml}, 0.5 \mu \mathrm{g} / \mathrm{ml}$, and $2 \mu \mathrm{g} / \mathrm{ml}$ anti-SLAM mAb to CD4 $4^{+}$CXCR5 ${ }^{+} \mathrm{T}_{\text {cells and }}$ detection of the percentage of Foxp $3^{+}$cells. Each experiment was repeated three times; ${ }^{* *} P<0.01 ;{ }^{*} P<0.05$; ns: no significant differences.

the number of Tfr cells increased in IL-21-deficient BXD2 mice, and Tfr cells transferred to BXD2 mice can reduce the formation of the germinal center and autoantibody production [16]. Although Tfr cells are considered a kind of cell that suppresses the immune response, Tsuji et al. found that Foxp $3^{+}$T cells could be transformed into Tfh cells by the loss of Foxp 3 and then induce the formation of a germinal center and the generation of $\operatorname{IgA}$ in Peyer's patches of the mouse intestine [43]. Another study reported that the percentage of Tfr cells in peripheral blood from child patients with idiopathic thrombocytopenic purpura (ITP) was decreased; in contrast, Tfh cells were increased, and the proportion of $\mathrm{Tfr} / \mathrm{Tfh}$ cells was reduced, which was associated with disease progression [44]. These results suggest that Tfh cells and Tfr cells have a complex and intimate connection. Since we found that adding anti-SLAM $\mathrm{mAb}$ to $\mathrm{CD} 4^{+} \mathrm{CXCR} 5^{+} \mathrm{T}$ cells 

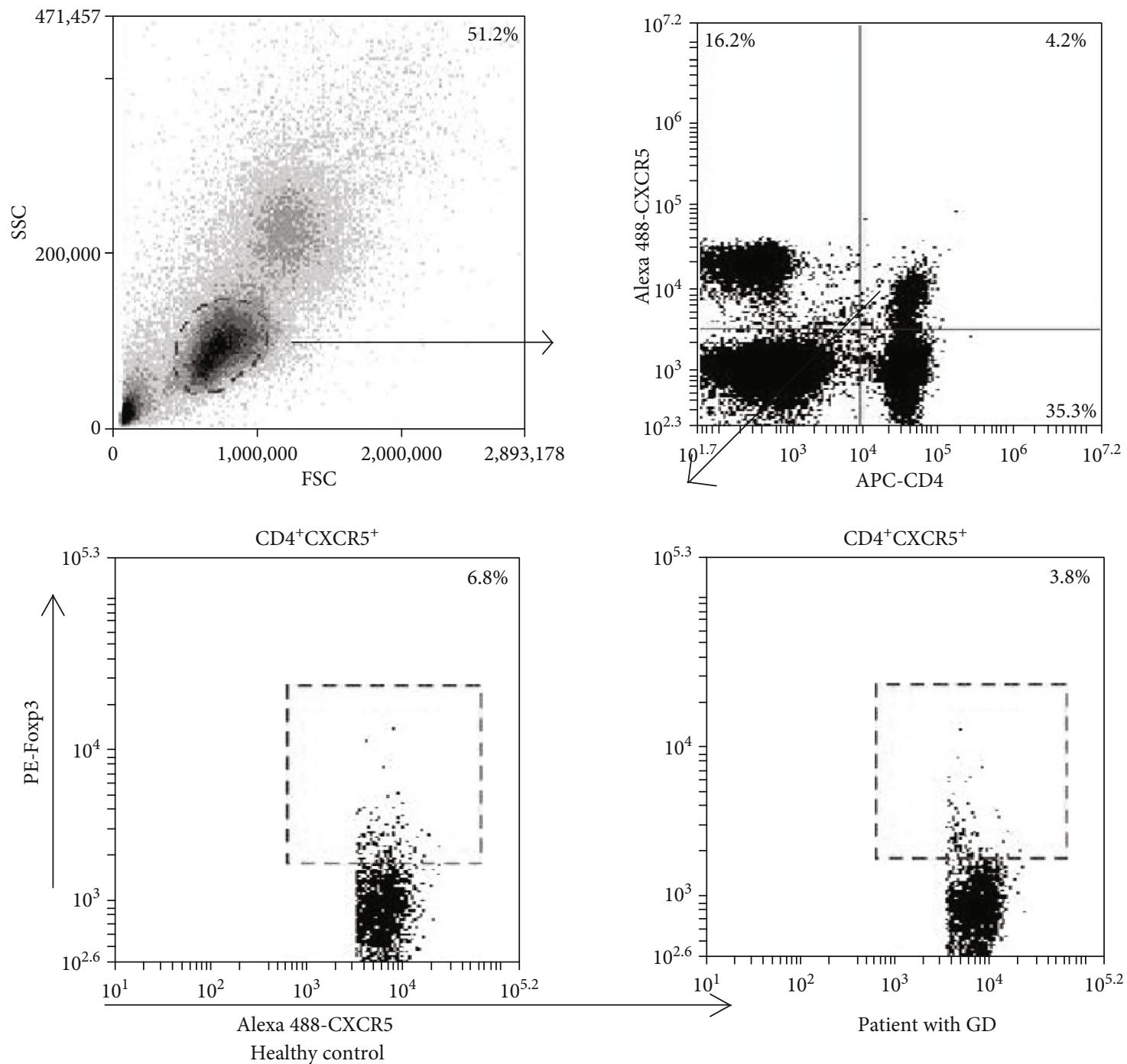

(a)

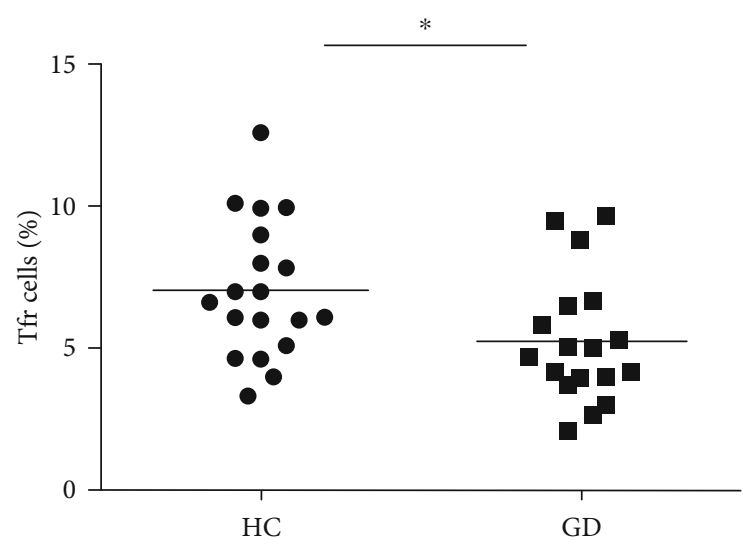

(b)

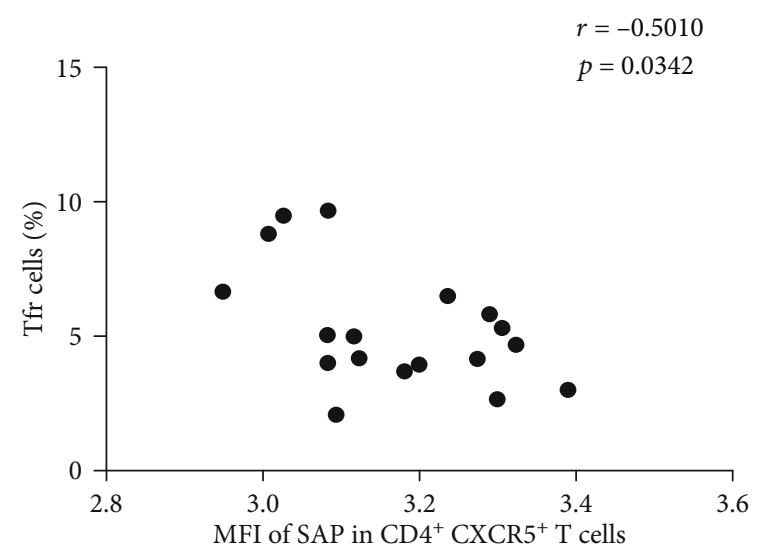

(c)

FIgURE 3: The percentage of Tfr cells in patients with GD. (a) Representative dot plots of CD $4^{+} \mathrm{CXCR} 5^{+}$Foxp $3^{+}$Tfr cells. (b) The percentage of Tfr cells from the patients with GD was lower than that in the healthy controls. (c) A negative correlation was found between the percentage of Tfr cells and the expression of SAP in $\mathrm{CD} 4{ }^{+} \mathrm{CXCR}^{+} \mathrm{T}$ cells from the patients with GD. ${ }^{*} P<0.05, n=18$. 


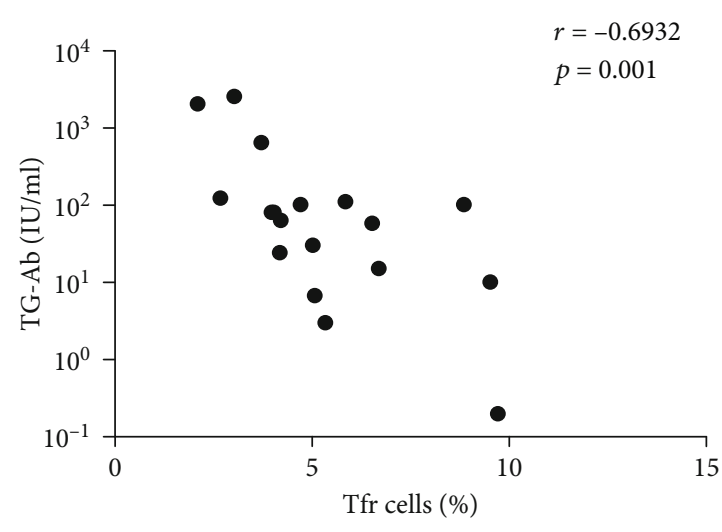

(a)

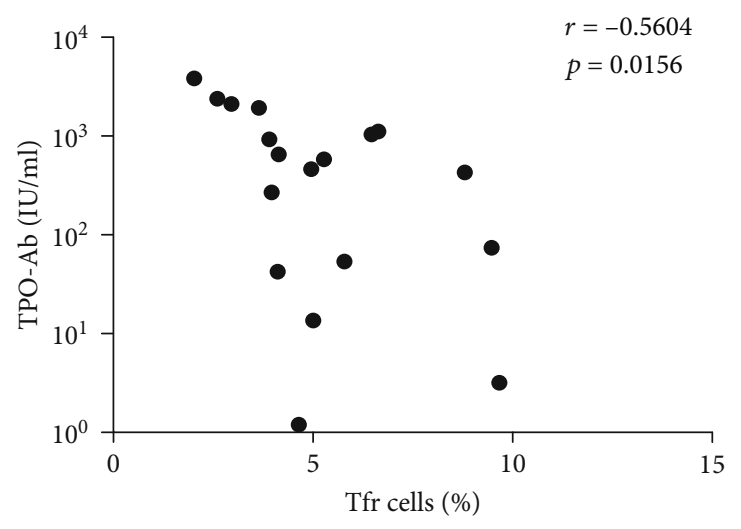

(b)

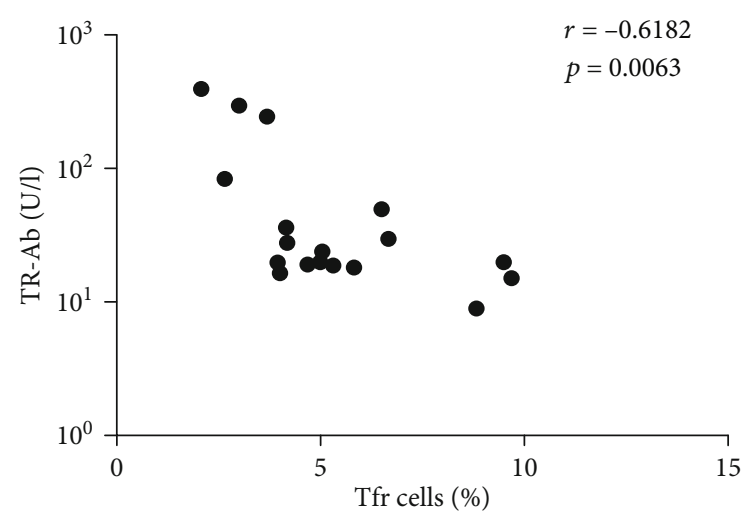

(c)

Figure 4: The correlations between the proportion of Tfr cells in PBMCs and the levels of (a) TR-Ab, (b) TPO-Ab, and (c) TG-Ab in serum from the patients with GD.

might decrease the proportion of Tfr cells and the previous results indicated that peripheral blood Tfh cells increased in GD patients, what is the effect on Tfr cells? Ultimately, our results showed that the proportion of peripheral blood Tfr cells considerably declined in the patients with GD. In addition, the proportion of Tfr cells was negatively correlated with the SAP level in $\mathrm{CD}^{+} \mathrm{CXCR}^{+} \mathrm{T}$ cells. All of the above results indicate that increased SLAM/SAP may be one of the reasons for the Tfr cell reduction in patients with GD.

Our results showed that the levels of SLAM on CD19+ B cells and SAP in $\mathrm{CD} 4^{+} \mathrm{CXCR}^{+}{ }^{+} \mathrm{T}$ cells were increased, SLAM may decrease the proportion of Tfr cells, and the proportion of Tfr cells correlates with disease severity. These data extend the understanding of the pathogenesis of GD and identify a potential biomarker. Further studies should focus on the mechanism of SLAM/SAP signaling pathways in Tfr cells.

\section{Data Availability}

The data supporting the conclusions of this article are included in the article.

\section{Ethical Approval}

This study was approved by the ethics committee of the Affiliated People's Hospital of Jiangsu University.

\section{Consent}

Patients gave written informed consent prior to collection of their blood and tissue specimens.

\section{Conflicts of Interest}

The authors declare that they have no potential conflict of interests.

\section{Authors' Contributions}

LG performed the experiments, analyzed the data, and wrote the paper; JY, XT, and HP performed the experiments; JT, $\mathrm{ZH}$, YL, and HX analyzed the data; SW designed the study and revised the paper. All authors read and approved the final manuscript.

\section{Acknowledgments}

This work was supported by the Jiangsu Province's Key Medical Talents Program (Grant nos. ZDRCB2016018 and QNRC2016456). 


\section{References}

[1] A. P. Weetman, "Autoimmune thyroid disease: propagation and progression," European Journal of Endocrinology, vol. 148, no. 1, pp. 1-9, 2003.

[2] T. Kocjan, B. Wraber, U. Repnik, and S. Hojker, "Changes in Th1/Th2 cytokine balance in Graves' desease," Pflügers Archiv, vol. 440, no. S1, pp. r094-r095, 2000.

[3] M. Vitales-Noyola, A. M. Ramos-Levi, R. Martínez-Hernández et al., "Pathogenic Th17 and Th22 cells are increased in patients with autoimmune thyroid disorders," Endocrine, vol. 57, no. 3, pp. 409-417, 2017.

[4] Q. Li, B. Wang, K. Mu, and J. A. Zhang, "The pathogenesis of thyroid autoimmune diseases: new T lymphocytes-cytokines circuits beyond the Th1-Th2 paradigm," Journal of Cellular Physiology, vol. 234, no. 3, pp. 2204-2216, 2019.

[5] C. Zhu, J. Ma, Y. Liu et al., "Increased frequency of follicular helper T cells in patients with autoimmune thyroid disease," The Journal of Clinical Endocrinology and Metabolism, vol. 97, no. 3, pp. 943-950, 2012.

[6] J. Chen, J. Tian, X. Tang et al., "MiR-346 regulates CD4(+)CXCR5 (+) T cells in the pathogenesis of Graves' disease," Endocrine, vol. 49, no. 3, pp. 752-760, 2015.

[7] S. Crotty, "Follicular helper CD4 T cells (TFH)," Immunology, vol. 29, no. 1, pp. 621-663, 2011.

[8] R. Morita, N. Schmitt, S. E. Bentebibel et al., "Human blood $\mathrm{CXCR}^{+} \mathrm{CD}^{+} \mathrm{T}$ cells are counterparts of $\mathrm{T}$ follicular cells and contain specific subsets that differentially support antibody secretion," Immunity, vol. 34, no. 1, pp. 108-121, 2011.

[9] H. W. Lim, P. Hillsamer, and C. H. Kim, "Regulatory T cells can migrate to follicles upon $\mathrm{T}$ cell activation and suppress GC-Th cells and GC-Th cell-driven B cell responses," The Journal of Clinical Investigation, vol. 114, no. 11, pp. 16401649, 2004.

[10] Y. Chung, S. Tanaka, F. Chu, R. I. Nurieva, G. J. Martinez, and S. Rawal, "Follicular regulatory T cells expressing Foxp3 and Bcl-6 suppress germinal center reactions," Nature medicin, vol. 17, no. 8, pp. 938-988, 2011.

[11] M. A. Linterman, W. Pierson, S. K. Lee, A. Kallies, S. Kawamoto, and T. F. Rayner, "Foxp $3^{+}$follicular regulatory T cells control the germinal center response," Nature Medicine, vol. 17, no. 8, pp. 975-982, 2011.

[12] V. R. Fonseca, F. Ribeiro, and L. Graca, "T follicular regulatory (Tfr) cells: dissecting the complexity of Tfr-cell compartments," Immunological Reviews, vol. 288, no. 1, pp. 112-127, 2019.

[13] M. J. McCarron and J. C. Marie, "TGF- $\beta$ prevents T follicular helper cell accumulation and B cell autoreactivity," The Journal of Clinical Investigation, vol. 124, no. 10, pp. 4375-4386, 2014.

[14] D. M. Zhao, A. M. Thornton, R. J. Dipaolo, and E. M. Shevach, "Activated CD4+CD25+T cells selectively kill B lymphocytes," Blood, vol. 107, no. 10, pp. 3925-3932, 2006.

[15] C. Jandl, S. M. Liu, P. F. Cañete et al., "IL-21 restricts T follicular regulatory $\mathrm{T}$ cell proliferation through Bcl- 6 mediated inhibition of responsiveness to IL-2," Nature Communications, vol. 17, no. 8, 2017.

[16] Y. Ding, J. Li, P. Yang et al., "Interleukin-21 promotes germinal center reaction by skewing the follicular regulatory $\mathrm{T}$ cell to follicular helper T cell balance in autoimmune BXD2 mice," Arthritis \& Rhematology, vol. 66, no. 9, pp. 2601-2612, 2014.
[17] G. Caoa, P. Wanga, Z. Cuia et al., "An imbalance between blood $\mathrm{CD}^{+} \mathrm{CXCR}^{+} \mathrm{Foxp}^{+}$Tfr cells and $\mathrm{CD} 4^{+} \mathrm{CXCR} 5^{+} \mathrm{Tfh}$ cells may contribute to the immunopathogenesis of rheumatoid arthritis," Molecular Immunology, vol. 125, pp. 1-8, 2020.

[18] Y. Gong, J. Tong, and S. Wang, "Are follicular regulatory T cells involved in autoimmune diseases?," Frontiers in Immunology, vol. 8, p. 1790, 2017.

[19] C. Detre, M. Keszei, X. Romero, G. C. Tsokos, and C. Terhorst, "SLAM family receptors and the SLAM-associated protein (SAP) modulate T cell functions," Seminars in Immunopathology, vol. 32, no. 2, pp. 157-171, 2010.

[20] P. Engel, M. J. Eck, and C. Terhorst, "The SAP and SLAM families in immune responses and X-linked lymphoproliferative disease," Nature Reviews Immunology, vol. 3, no. 10, pp. 813-821, 2003.

[21] M. Claus, D. Urlaub, F. Fasbender, and C. Watzl, "SLAM family receptors in natural killer cells - mediators of adhesion, activation and inhibition via cis and trans interactions," Clinical Immunology, vol. 204, no. 1, pp. 37-42, 2019.

[22] O. Dienz, V. L. DeVault, S. C. Musial et al., "Critical role for SLAM/SAP signaling in the thymic developmental programming of IL-17- and IFN- $\gamma$-producing $\gamma \delta$ T cells," Journal of Immunology, vol. 204, no. 6, pp. 1521-1534, 2020.

[23] A. Veillette, Z. Dong, and S. Latour, "Consequence of the SLAM-SAP signaling pathway in innate-like and conventional lymphocytes," Immunity, vol. 27, no. 5, pp. 698-710, 2007.

[24] H. Minagawa, K. Tanaka, N. Ono, H. Tatsuo, and Y. Yanagi, "Induction of the measles virus receptor SLAM (CD150) on monocytes," The Journal of General Virology, vol. 82, no. 12, pp. 2913-2917, 2001.

[25] M. Kruse, E. Meinl, G. Henning et al., "Signaling lymphocytic activation molecule is expressed on mature CD83+ dendritic cells and is up-regulated by IL-1 beta," Journal of immunology (Baltimore, Md: 1950), vol. 167, no. 4, pp. 1989-1995, 2001.

[26] A. Veillette, M. E. Cruz-Munoz, and M. C. Zhong, "SLAM family receptors and SAP-related adaptors: matters arising," Trends in Immunology, vol. 27, no. 5, pp. 228-234, 2006.

[27] M. L. Vilar, M. S. Frutuoso, S. M. Arruda, D. M. Lima, C. S. Bezerra, and M. M. Pompeu, "The role of the SLAM-SAP signaling pathway in the modulation of CD4+ T cell responses," Brazilian Journal of Medical and Biological Research, vol. 44, no. 4, pp. 276-282, 2011.

[28] A. Y. Chan, J. M. Westcott, J. M. Mooney, E. K. Wakeland, and J. D. Schatzle, "The role of SAP and the SLAM family in autoimmunity," Current Opinion in Immunology, vol. 18, no. 6, pp. 656-664, 2006.

[29] S. Latour, R. Roncagalli, R. Chen et al., "Binding of SAP SH2 domain to FynT SH3 domain reveals a novel mechanism of receptor signalling in immune regulation," Nature Cell Biology, vol. 5, no. 2, pp. 149-154, 2003.

[30] J. L. Cannons, L. J. Yu, D. Jankovic et al., "SAP regulates T cellmediated help for humoral immunity by a mechanism distinct from cytokine regulation," The Journal of Experimental Medicine, vol. 203, no. 6, pp. 1551-1565, 2006.

[31] S. Crotty, E. N. Kersh, J. Cannons, P. L. Schwartzberg, and R. Ahmed, "SAP is required for generating long-term humoral immunity," Nature Cell Biology, vol. 421, no. 6029, pp. 282287, 2003.

[32] P. Ferrante, M. L. Fusi, M. Saresella et al., "Cytokine production and surface marker expression in acute and stable multiple sclerosis: altered IL-12 production and augmented 
signaling lymphocytic activation molecule (SLAM)-expressing lymphocytes in acute multiple sclerosis," Journal of Immunology, vol. 160, no. 3, pp. 1514-1521, 1998.

[33] P. Isomäki, G. Aversa, B. G. Cocks et al., "Increased expression of signaling lymphocytic activation molecule in patients with rheumatoid arthritis and its role in the regulation of cytokine production in rheumatoid synovium," Journal of Immunology, vol. 159, no. 6, pp. 2986-2993, 1997.

[34] M. P. Karampetsou, D. Comte, K. Kis-Toth, V. C. Kyttaris, and G. C. Tsokos, "Expression patterns of signaling lymphocytic activation molecule family members in peripheral blood mononuclear cell subsets in patients with systemic lupus erythematosus," PLoS One, vol. 12, no. 10, 2017.

[35] J. Yang, L. Geng, Y. Ma, X. Tang, H. Peng, and J. Tian, “SLAMs negatively regulate IL-21 production in Tfh-like cells from allergic rhinitis patients," Journal of Asthma and Allergy, vol. 14, 2021.

[36] M. A. Dragovich and A. Mor, "The SLAM family receptors: potential therapeutic targets for inflammatory and autoimmune diseases," Autoimmunity Reviews, vol. 17, no. 7, pp. 674-682, 2018.

[37] J. Tian, K. Rui, Y. Hong et al., "Increased GITRL impairs the function of myeloid-derived suppressor cells and exacerbates primary Sjögren syndrome," Journal of Immunology, vol. 202, no. 6, pp. 1693-1703, 2019.

[38] M. M. McCausland, I. Yusuf, H. Tran, N. Ono, Y. Yanagi, and S. Crotty, "SAP regulation of follicular helper CD4 T cell development and humoral immunity is independent of SLAM and Fyn kinase," Journal of Immunology, vol. 178, no. 2, pp. 817828, 2007.

[39] M. P. Karampetsou, D. Comte, A. Suárez-Fueyo et al., "Signaling lymphocytic activation molecule family member 1 engagement inhibits $\mathrm{T}$ cell- $\mathrm{B}$ cell interaction and diminishes interleukin-6 production and plasmablast differentiation in systemic lupus erythematosus," Arthritis and Rheumatism, vol. 71, no. 1, pp. 99-108, 2019.

[40] B. G. Cocks, C. C. Chang, J. M. Carballido, H. Yssel, J. E. de Vries, and G. Aversa, "A novel receptor involved in T-cell activation,” Nature, vol. 376, no. 6537, pp. 260-263, 1995.

[41] N. Wang, P. J. Halibozek, B. Yigit et al., "Negative regulation of humoral immunity due to interplay between the SLAMF1, SLAMF5, and SLAMF6 receptors," Frontiers in Immunology, vol. 6, 2015.

[42] M. B. Browning, J. E. Woodliff, M. C. Konkol et al., "The T cell activation marker CD150 can be used to identify alloantigenactivated $\mathrm{CD}^{+} 25^{+}$regulatory T cells," Cellular Immunology, vol. 227, no. 2, pp. 129-139, 2004.

[43] M. Tsuji, N. Komatsu, S. Kawamoto et al., "Preferential generation of follicular B helper T cells from Foxp3+ T cells in gut Peyer's patches," Science (New York, N.Y.), vol. 323, no. 5920, pp. 1488-1492, 2009.

[44] Y. Cui, Y. Guan, W. Liu, Y. Li, H. Li, and M. Guo, "The changes of circulating follicular regulatory $\mathrm{T}$ cells and follicular T helper cells in children immune thrombocytopenia," Chin J Hematol, vol. 35, no. 11, pp. 980-984, 2014. 